Article

\title{
Spatial Planning Policy for Sustainability: Analysis Connecting Land Use and GHG Emission in Rural Areas
}

\author{
Michele Pezzagno ${ }^{\circledR}$, Anna Richiedei ${ }^{*}$ and Maurizio Tira \\ Department of Civil, Environmental, Architectural Engineering and Mathematics, Università degli Studi di \\ Brescia (IT), 25123 Brescia, Italy; michele.pezzagno@unibs.it (M.P.); maurizio.tira@unibs.it (M.T.) \\ * Correspondence: anna.richiedei@unibs.it
}

Received: 19 December 2019; Accepted: 25 January 2020; Published: 28 January 2020

check for updates

\begin{abstract}
Anthropogenic greenhouse gas (GHG) emissions are the highest they have ever been and the climate change they have triggered is having consequences on both human and natural systems. The aim of the paper is to demonstrate that an integrated reading of urban and rural land uses in relation to GHG emissions is feasible and useful at the regional level in order to reach emissions reduction. The Po Valley in Italy is an emblematic case study because its features are unique in Europe for high population density, urban sprawl, intensive agriculture, livestock management and consequently high emission levels. The methodology examines the total GHG emissions in relation to urban and rural areas. Between 2000 and 2010, the trend of $\mathrm{CO}_{2}$-equivalent emissions for the macro-regions of Italy shows a national decrease in contrast to the area of our case study which has seen a steady increase and growth trend over time. The paper analyzes some possible reasons linked to this anomaly, and it presents an estimation of the $\mathrm{CO}_{2}$-equivalent emissions related to the use of agricultural land. The main output of the paper is a new overview for research that aims to propose integrated solutions and policies at the local level with a wider vision focused on GHG emission knowledge, supported by Strategic Environmental Assessment.
\end{abstract}

Keywords: agricultural areas; Strategic Environmental Assessment; spatial planning policy implications

\section{Introduction}

Anthropogenic Greenhouse Gas (GHG) emissions are the highest they have ever been, and the climate change triggered by them is having consequences on both human and natural systems $[1,2]$. The main trend in European Union (EU) greenhouse gas emission by the European Environment Agency (EEA) from 1990 to 2016 shows a general decrease (-24\%) due to a combination of factors: lower emissions in industrial sectors, economic recession, energy efficiency improvements from better insulation standards in buildings and a strong increase in the use of biomass for energy, amongst others. [3]. The three most polluting elements are: $\mathrm{CO}_{2}, \mathrm{CH}_{4}$ and $\mathrm{N}_{2} \mathrm{O}$ and they are also the most significantly associated with urban phenomena. In the list of EU-28 contributions to total GHG emissions, Italy is in the fourth position with $10 \%$ of total emissions in 2016. The leading contributors are Germany (21\%), UK (11\%) and France (10.6\%) [3]. The International Panel for Climate Change (IPCC) has also indicated that the $10 \%$ increase of $\mathrm{GtCO}_{2}$-eq that occurred between 2000 and 2010 has come primarily from energy production $(47 \%)$, manufacturing $(30 \%)$, transport (11\%) and buildings $(3 \%)$. The agriculture sector is considered part of a strategy for the mitigation and recovery of $\mathrm{CO}_{2}$, as codified in the acronym AFOLU (Agriculture, Forestry and Other Land Use) of the WGIII [1,4]. Other studies have deepened the topic of renewable energy sources, distinguishing phenomena 
and analyzing rural and urban areas (districts) [5] or for different urban density conditions [6]. In general, the scientific research is currently divided into two principal topics: the first focused on city environmental problems [7-9] and the second focused on GHG emissions in relation to rural development [10-12]. Feliciano et al. [13] investigated "rural land uses" and greenhouse gas emissions in Scotland, demonstrating that an assessment of GHG emissions related to rural land uses at the regional level is feasible. Engineering rural development research most frequently uses the following keywords: biomass, biogas, performance, anaerobic digestion, soil, methane and calorific value [14]. The attention to the "land use" vision is missing.

At the European and national level, the different policies [10] are properly treated separately, but at the regional level an integrated vision is absolutely needed to reduce GHG emission.

In order to overlap this gap, detailed investigations should focus on anthropized and densely populated areas with the aim of proposing policy and actions for the reduction of $\mathrm{CO}_{2}$ emissions in cities. Seravalli et al. [15] state that in Europe $65 \%$ of the population lives in cities with less than 500,000 inhabitants (in the USA this situation occurs for only $37 \%$ of the population). On the other hand, in contrast to big cities, medium and small cities are characterized by a healthy urban environment and stronger connections with natural and rural areas [15]. The rural component should represent a reserve that is able to counteract GHG emissions. However, rural areas are also settled with livestock farming that has an impact on global warming, generating about $10 \%$ of total European GHG emissions [16]. In other words, the rural areas can play a significant double-dealing role: recovery and production of $\mathrm{CO}_{2}$, dependent upon the land use and agricultural management [17].

The goal of the paper is to try to read in a unique framework the aspects mentioned above in order to better understand the phenomena in relation to land-use planning and to improve the Strategic Environmental Assessment (SEA) at the local level. The proposed case study analyzes one of the emblematic situations in Europe (the Po Valley region). The Po Valley is one of the most densely populated areas of Italy (over 2000 inhabitants per $\mathrm{km}^{2}$ ) [18]. This figure is significant in the European context: the Italian average for 2015 is $201 \mathrm{inh} / \mathrm{km}^{2}$, well above the European average of $115.5 \mathrm{inh} / \mathrm{km}^{2}$. In particular, Lombardy, at the center of the Po Valley, reaches $419 \mathrm{inh} / \mathrm{km}^{2}$, close to that of the Netherlands $\left(498 \mathrm{inh} / \mathrm{km}^{2}\right)$ and Belgium $\left(368 \mathrm{inh} / \mathrm{km}^{2}\right)$ [19]. This figure goes hand in hand with the numbers for GHG emissions. In addition, the data for urban sprawl, like Urban Permeant Units (UPU) $(+7 \%)\left(+0.14 \mathrm{UPU} / \mathrm{m}^{2}\right)$ and percentage of built-up area $(+4.6 \%)$ are higher than the 2006-2009 European average [20]. For this reason, most studies focus on urban area emissions. However, some studies show that it is important to analyze a region as a whole rather than a single city, as the city is responsible for only about half of the total emissions [21]. The lack of a clear separation between urban and rural areas is also a special case and can condition rural area spatial planning and its integration with urban planning.

This research examines the total emissions of GHG in relation to urban areas, and then the emissions related to the areas used exclusively for agriculture and livestock farming. The case study is as representative as possible: it presents different morphologic areas (mountains, hills, plains, lakes and rivers) and different relations between rural and urban areas, and highlights the problem of emissivity from rural areas in the plain. The general analysis covers the Lombardy region and then in-depth the case of the Province of Brescia.

\section{Materials and Methods}

\subsection{Materials}

The Lombardy region is the most populated in Italy (10,019,166 inh) and is composed of 1516 municipalities. Only one city (Milan) has a population greater than one million inhabitants and only three cities have more than 100,000 inhabitants (Brescia, Monza and Bergamo). The average municipality population is 6600 (data processing of [22]) while $69 \%$ have less than 5000 inhabitants. 
The Province of Brescia (in the center of the Po Valley) it is made up of 205 municipalities with characteristics varying for the number of inhabitants and extensions. The average population for a municipality is 6150 inhabitants and, as with the Lombardy region, $65 \%$ of municipalities have less than 5000 inhabitants. It has a strong productive components of both agriculture (in the south) and manufacturing (in the north) with a central urban area. It is at the center of the Po Valley Linear Metropolitan System-the LiMeS structure (high anthropogenic pressure band) and it presents two low-pressure anthropogenic bands identified by Busi and Pezzagno as a Neighboring Mega Ecological System-NeMESys [23] (Figure 1) in the PRIN project 2007 "From the metropolitan city to the metropolitan corridor: the case of Po Valley corridor"( PRIN project is a "Projects for Research of Relevant National Interest" (PRIN) are funded by the Italian Ministry for Education, University and Research through a tender. The description of the phenomenon of the Linear Metropolitan System (LiMeS) is one of the original results achieved in the cited PRIN project. The research units involved in the cited PRIN project belonged to: University of Brescia (leader), Polytechnic of Milan, University of Padova, Polytechnic of Turin, University of Udine). The territory of Northern Italy is characterized by the Po Valley Linear Metropolitan System (LiMeS), an urban continuum aligned along one mobility directrix with high levels of anthropogenic pressure. The Po Valley LiMeS has an approximate extension of $500 \mathrm{~km}$ and a population of 16 million people: polycentric areas, which are characterized by the aggregation of a series of centers with partial non-specific dominance, constitute it. These polycentric conurbations are distinguished by a clear-cut morphological identity regarding the spatial distribution of activities (city-network) accompanied by flows of socio-economic integration of the main growth factors (employment, services, knowledge and social capital). In other words, they are urban centers and areas with intense demographic and productive activity, aligned along a specific axis, with a metropolitan system of relations. This urban area constitutes the limit (limes means limit in the Latin language) between two macro-areas characterized by specific environmental systems. These systems called NeMESys (Neighboring Mega Ecological Systems) generally result in being deeply different from the LiMeS areas from a morphological, environmental and landscape point of view, and are different from one another: the first one is constituted by "the alpine and prealpine system" and the second one is constituted by "the Po Valley irrigated plain system" [24].

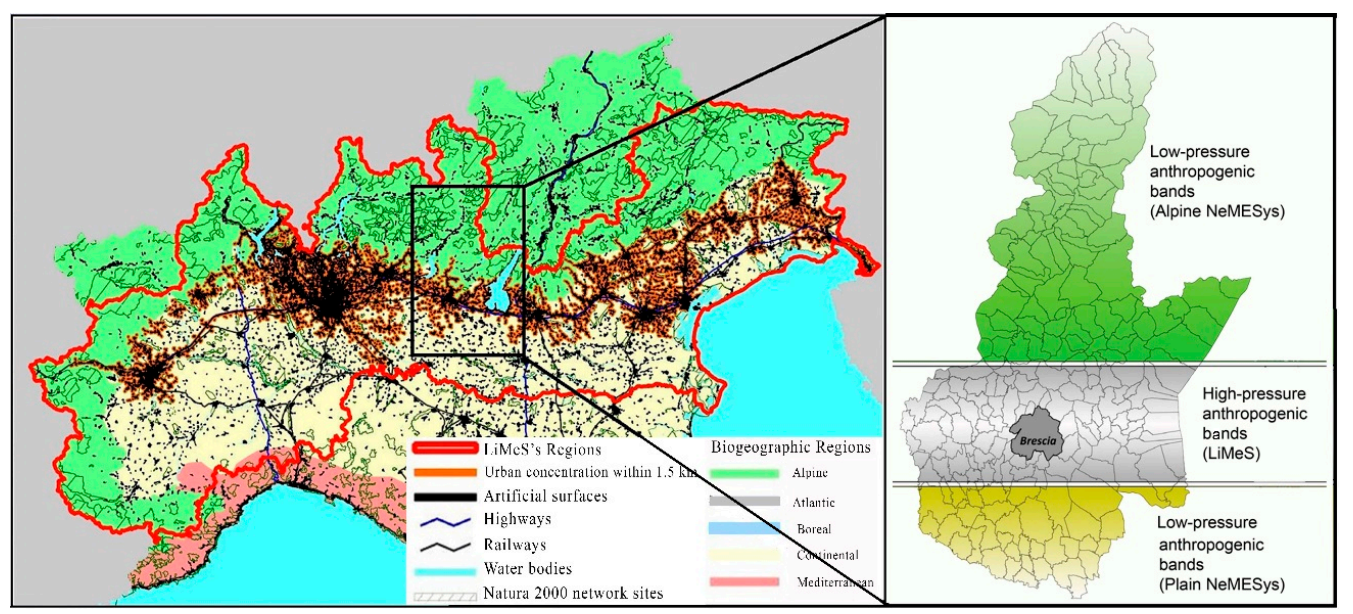

Figure 1. On the left, the LiMeS Po Valley structure: the Italian Region involved in LiMeS in red, the artificial surfaces in black and the urban concentration within $1.5 \mathrm{~km}$ in brown [25]. On the right, the Province of Brescia and the high anthropogenic pressure band (in the middle) and the two low-pressure anthropogenic bands (NeMESys - in the North and in the South).

Regardless of the current Italian territorial system (Ref. L. No. 56 of April 7, 2014), the reference to the province in the context of land management remains significant even in relation to rural policy issues recently transferred under regional jurisdiction. 
Another feature characterizing the Po Valley (and the case study) is its meteorological situation. The concentration levels of pollutants in the air depend not only on the type of emissions, but also on the meteorological conditions, which can affect the mechanisms of diffusion and dispersion. The conditions of the Po Valley are unique and characterized by atmospheric stability with low winds and thermal inversion [26] in addition to sun-generated secondary air pollutants (e.g., $\mathrm{O}_{3}$ ).

The significant data variance found in the Po Valley leads to an analysis on a different scale where the high level of emissivity also in rural areas is highlighted. The Po Valley is characterized by intensive agricultural activity, especially livestock farming. Lombardy is the third European region (NUT2) for agricultural production and more than half of its activity is related to livestock farming [27]. The data variance between national and regional scales can be substantially different. For example, Germany has a higher number for cows' milk production on farms, but "there were stark contrasts in the apparent milk yield per dairy cow at the regional level in 2016. It was highest in Lombardy" (2012-2016) [28]. Hence, not only is the absolute data important, but also the land management methods used for agricultural and livestock activities. The research of Grešlová et al., for example, confirms "that shifts towards less animal-based food production have a positive effect on the agro-ecological energy returns on investment" and it reveals "significant insights on the interrelation of energy use, land use system and socioeconomic and political settings of society" [29,30]. Furthermore, in addition to the urban areas, "with farmers managing almost half of the EU's land area, the agricultural sector is a major source of pressure on Europe's environment" [31]. The EU Common Agricultural Policy (CAP), the main tool supporting the EU agriculture, "has encouraged the sector to become rapidly modernized and agricultural production itself to increase intensification" as an answer to the growing globalization of the world's economy [31]. However, "pollution from agriculture is a major pressure on the quality of ground and surface water" [31] and the emissions of $\mathrm{N}_{2} \mathrm{O}$ and $\mathrm{CH}_{4}$ cannot be neglected. In the context of the sustainability of human activities through the management of air quality and the limitation of pollutant emissions in the atmosphere, quantitative information on emissions from different sources is increasingly needed. For this purpose, GHG emission inventories are proposed as a method for the collection of information and technological, economic and territorial data, based on verifiable and updateable procedures and methodologies, which allow us to identify sources of pollution and the quantity and type of pollutants emitted segregated by province and district [25], while the EU Effort Sharing Decision (ESD) [32] data are considered relevant.

In Italy, the preliminary emission inventories for each Region were originally governed at the regulatory level by Articles 4 and 5 of the D.P.R. 24 May 1988, no. 203 (http://www.isprambiente.gov.it/ files/aria/d.p.r.24maggio1988n.203.pdf) and from the D.M. May 20, 1991 (https://www.gazzettaufficiale. it/eli/id/1992/02/06/092A0482/sg). This last decree established for the first time the "criteria for a census on emissions of atmospheric pollutants for the purpose of preparing an inventory of these emissions in the atmosphere, in the context of the plans for the protection and enhancement of air quality", in which inventory means a coherent collection of emission data segregated by:

- Economic activity;

- Territorial unit;

- Time Period;

- Fuel used, but only if it is seen as relevant.

With the Legislative Decree No. 351 on 4 August 1999 (https://www.camera.it/parlam/leggi/ deleghe/99351dl.htm), the Directive 96/62/CE (https:/eur-lex.europa.eu/legal-content/EN/TXT/?uri= CELEX\%3A31996L0062) on air quality, which defines the overall picture of air pollution and the assessment and management of air quality, has been transposed into the national legislation. The DM 261/2002 (https://www.gazzettaufficiale.it/eli/id/2002/11/20/002G0294/sg) identifies the criteria derived from the Guidelines for the Realization of Inventories of Emissions taken from the Centro Tematico Nazionale Atmosfera, Clima, Emissioni (CTN-ACE). The most widely used method for estimating emissions is that developed under the CORINAIR (COoRdination INformation AIR) project, promoted 
and coordinated by the DG XI in the European Community under the CORINE experimental program (COoRdinated INformation on the Environment in the European Community) and undertaken by the Commission of European Communities following the Council Decision of 27 June 1985.

The Inventory for the Lombardy Region has been developed according to this methodology and provides estimates of the total annual emissions of macro and micro-pollutants, segregated by emissive activity at the various levels of SNAP classification (Selected Nomenclature for Air Pollution) [33] and divided geographically on a municipal scale.

The greenhouse gas emission data used for the estimation of emissions in the case study presented in this paper have been taken from the INEMAR database (INventario EMissioni ARia), managed and developed by the Regional Environmental Protection Agency of Lombardy (open source). This database divides emissions into 11 macro-sectors or emission categories:

1. Production of energy and fuel transformation;

2. Non-industrial combustion;

3. Industrial combustion;

4. Manufacturing processes;

5. Extraction and distribution of fuels;

6. Use of solvents;

7. Transport by road;

8. Other moving sources and machinery;

9. Waste treatment and disposal;

10. Agriculture;

11. Other sources and recovery areas.

This refers to the European protocol regarding the collection of greenhouse gases European Monitoring Evaluation Program-COoRdination INformation AIR (EMEP-CORINAIR) [33], which is in line with the international guidelines of the IPCC [34].

\subsection{Methods}

According to INEMAR, the ideal methodology for the realization of an emissions inventory is the direct quantification, through measurements, of all emissions from the different types of sources, for each area and time frame. However, the "analytical" approach can only be used for certain types of pollutants (e.g., sulfur dioxide, nitrogen oxides, carbon monoxide) and sources, typically large industrial plants (e.g., thermoelectric plants, incinerators, cement plants), whose emissions are generally very significant and therefore strictly controlled through continuous monitoring systems.

Accordingly, it is necessary to resort to the most common approach for emission inventories, which calculates emissions based on an indicator that characterizes source activity and an emission factor, specific to its source, industrial process and purification technology. This method is consequently based on a linear relationship between the activity of the source and its emission, that in general can be indicated as follows:

$$
\mathrm{Ei}=\mathrm{A} \cdot \mathrm{Fei}
$$

where:

$\mathrm{Ei}=$ pollutant emission $\left(\mathrm{g}_{\text {year }}{ }^{-1}\right)$;

$\mathrm{A}=$ activity indicator, for example: quantity produced, fuel consumption $\left(\mathrm{t}\right.$ year $\left.{ }^{-1}\right)$;

Fei $=$ pollutant emission factor $\mathrm{i}\left(\mathrm{g} \mathrm{t}^{-1}\right.$ of product).

The validity of this estimate depends on the precision of the "emission factors", and becomes more accurate in the function of the individual production process identification which permits the use of specific emission factors characteristic of that particular type of plant. 
In particular, emissions of $\mathrm{CO}_{2}$-equivalents, on which the paper is focused, are expressed on the basis of the contribution of the individual pollutants relative to their contribution to the greenhouse effect:

$$
\mathrm{CO}_{2} \text {-eq }=\Sigma \mathrm{GWi} \cdot \mathrm{Pi}
$$

where:

$\mathrm{CO}_{2}$-eq $=\mathrm{CO}_{2}$-equivalent emissions in $\mathrm{kt} /$ year

$\mathrm{GWi}=$ "Global Warming Potential" relative to the contribution of polluting substances as proposed by IPCC and its coefficients for $\mathrm{CO}_{2}, \mathrm{CH}_{4}$ and $\mathrm{N}_{2} \mathrm{O}$ molecules [] that are the most relevant for the urban phenomena.

$\mathrm{Pi}=$ Emission factor of individual pollutant (as referenced in the previously mentioned CORINAIR project in the version denominated Selected Nomenclature for sources of Air Pollution-SNAP 97).

The method of analysis proposed by our research group is developed in two phases: the first phase is established on a large territorial scale with a low level of data detail; the second phase on a smaller, but still representative, territorial scale (the province of Brescia), which goes into more precise details. For this method of investigation, a procedure of successive approximations is required.

The first phase of the method indicates the evaluation and delineation on thematic maps of the following territorial indicators:

- Absolute emissions of $\mathrm{CO}_{2}$-equivalent (kt) calculated using the INEMAR method;

- Emission density expressed in thousands of tons of $\mathrm{CO}_{2}$-equivalent on the municipal administrative area.

Based on the correspondence of the method to the territorial reality described by LiMeS, the approximations adopted were further reduced and territorially located, and the method applied on a more detailed scale. These modifications were made possible by refining the following elements:

- The municipal administrative area was replaced by the urbanized area, as defined by the Corine Land Cover (CLC) project [35] for artificial surfaces, or categories 111 to 142;

- Absolute emissions of $\mathrm{CO}_{2}$-equivalents were replaced by those directly from urbanized areas. The contribution of the Agriculture sector, (agricultural and livestock production) forestry and natural areas in general (macro-sectors 10 and 11) have been removed from the total emission values.

The reference map is the Digital Terrain Model (DTM), on which the main lake basins and watercourses, roads and highways and artificial surfaces have been inserted, in order to geo-localize the case study.

The following indicators were added to the regional scale:

- The ratio between the density of emissions and the density of residential areas;

- Density of $\mathrm{PM}_{2.5}$ emissions expressed in $\mathrm{kg}$ of $\mathrm{PM}_{2.5}$ on the artificial surface.

- On a provincial scale, these additional indicators were also investigated:

- Emissions of $\mathrm{CO}_{2}$-equivalent pro capita expressed in tons of $\mathrm{CO}_{2}$-equivalent per inhabitant;

- The density of emissions from the macro-sector of agriculture expressed in tons of $\mathrm{CO}_{2}$-equivalents from the macro-sector 11 compared to the Utilized Agricultural Surface (UAS);

- The density of agricultural emissions expressed in tons of $\mathrm{CO}_{2}$-equivalent of the agricultural component (relative to crops with or without fertilizers) with respect to the UAS;

- The density of livestock emissions expressed in tons of $\mathrm{CO}_{2}$-equivalent from the livestock component (relating to enteric fermentation sources and waste management of organic and nitrogen compounds) with respect to the UAS.

The GIS is used as a means of visualizing data and for analysis operations [36]. 


\section{Results}

The trend of $\mathrm{CO}_{2}$-equivalent emissions between 2000 and 2010 for the macro-regions of Italy (North, Center and South) shows a national decrease compared to the geographical area of our case study (the Lombardy Region and the Province of Brescia). In particular, the Lombardy Region has seen a steady increase and growth trend over time. The study of the Province of Brescia analyzed between 2003 and 2010 has shown (Table 1) a significant decrease in the following macro-sectors: production of energy, manufacturing and extraction and distribution of fuels. However, emissions in the following macro-sectors have increased: agriculture, solvent use, waste treatment and disposal and non-industrial combustion. The most emissive macro-sectors are transport and industrial combustion.

Table 1. Variation $(\Delta)$ of emissions in different macro-sectors in the province of Brescia from 2003 to 2010 .

\begin{tabular}{|c|c|}
\hline Macro-sectors & $\Delta$ emissions $2003-2010\left(\mathrm{ktCO}_{2}-\mathrm{eq}\right)$ \\
\hline 1. Production of energy and fuel transformation & -366 \\
\hline 2. Non-industrial combustion & +131 \\
\hline 3. Industrial combustion & +502 \\
\hline 4. Manufacturing processes & -76 \\
\hline 5. Extraction and distribution of fuels & -40 \\
\hline 6. Use of solvents & +49 \\
\hline 7. Transport by road & +286 \\
\hline 8. Other moving sources and machinery & -166 \\
\hline 9. Waste treatment and disposal & +103 \\
\hline 10. Agriculture & +42 \\
\hline 11. Other sources and recovery areas & -1196 \\
\hline
\end{tabular}

Analyzing the segregated data in the case study of Brescia presents data that countertrend the national tendency and indicate a net increase of greenhouse gas emissions over the time interval considered.

The results of the indicators described above are reported as follows.

The absolute $\mathrm{CO}_{2}$-equivalent emission data for the Lombardy region show predictable figures, that is, the areas with higher emission values are from:

- Dense urban environments such as provincial capitals;

- Industrial environments, in particular when there is a presence of activities such as cement plants, thermoelectric power plants, petrochemicals, etc.;

- Agricultural environments (especially in the triangle among provincial capitals Brescia, Mantova and Cremona).

The thematic map representation shows a circle proportional to the emission of $\mathrm{CO}_{2}$-equivalent in a barycentric position to the perimeter of the municipal boundary, allowing us to compare it with a representation of the Po Valley proposed by the already mentioned PRIN Project 2007 and following the same approach with statistics regarding the residential population (Figure 2).

By analyzing the emission density indicators, the congruence of specific characteristics of the LiMeS [23] in the Po Valley is verified. Specifically, by relating the indicators between the emissions and the surfaces relative to the urban areas (Figure 3), condensation of emission densities in the connection between Milan and Bergamo, along the motorway axis, is noted. The connection between Bergamo and Brescia, however, is slightly less accentuated, despite the numerical values underlying the chromatic ones being very close to that category. 


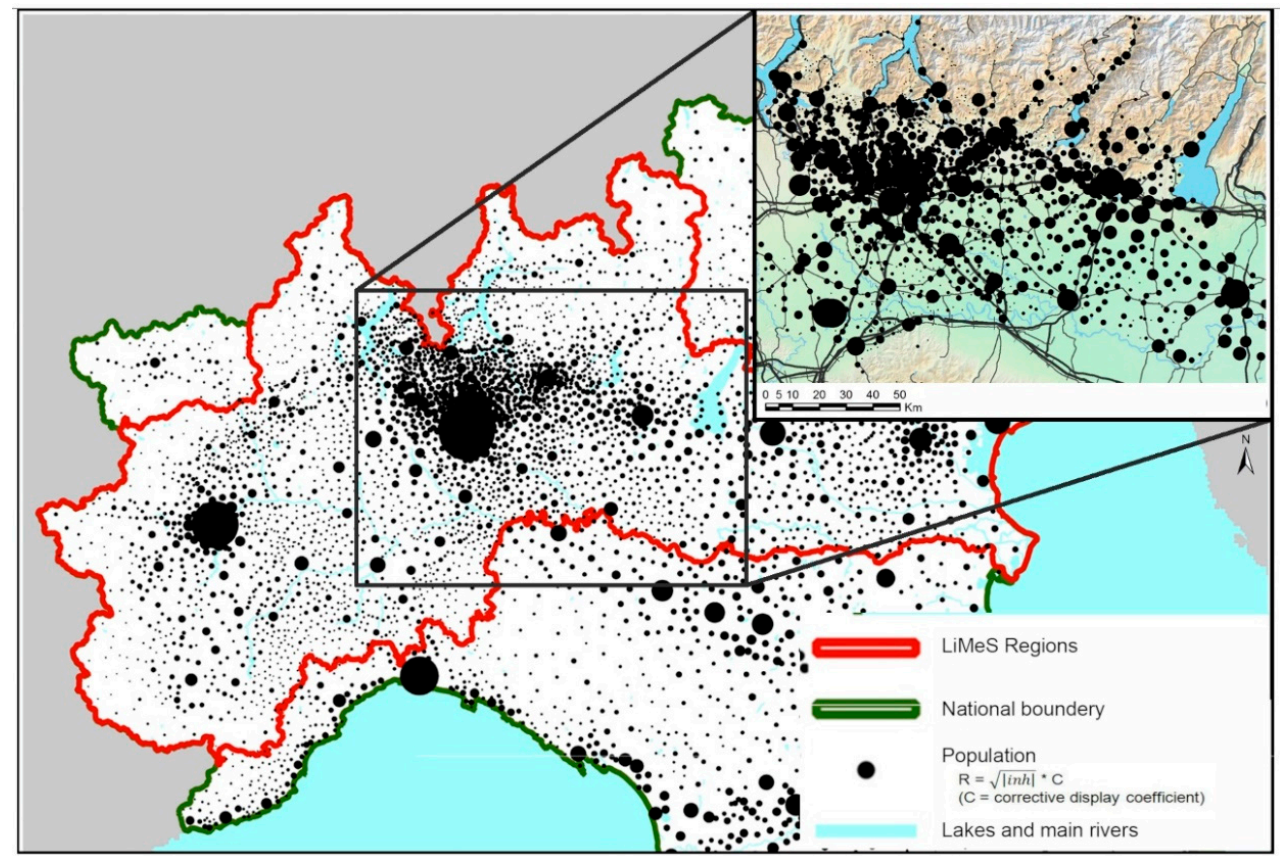

Figure 2. Comparison between emissions of $\mathrm{CO}_{2}$-equivalent and residential population (development from the table by Docchio and Pezzagno [25]).

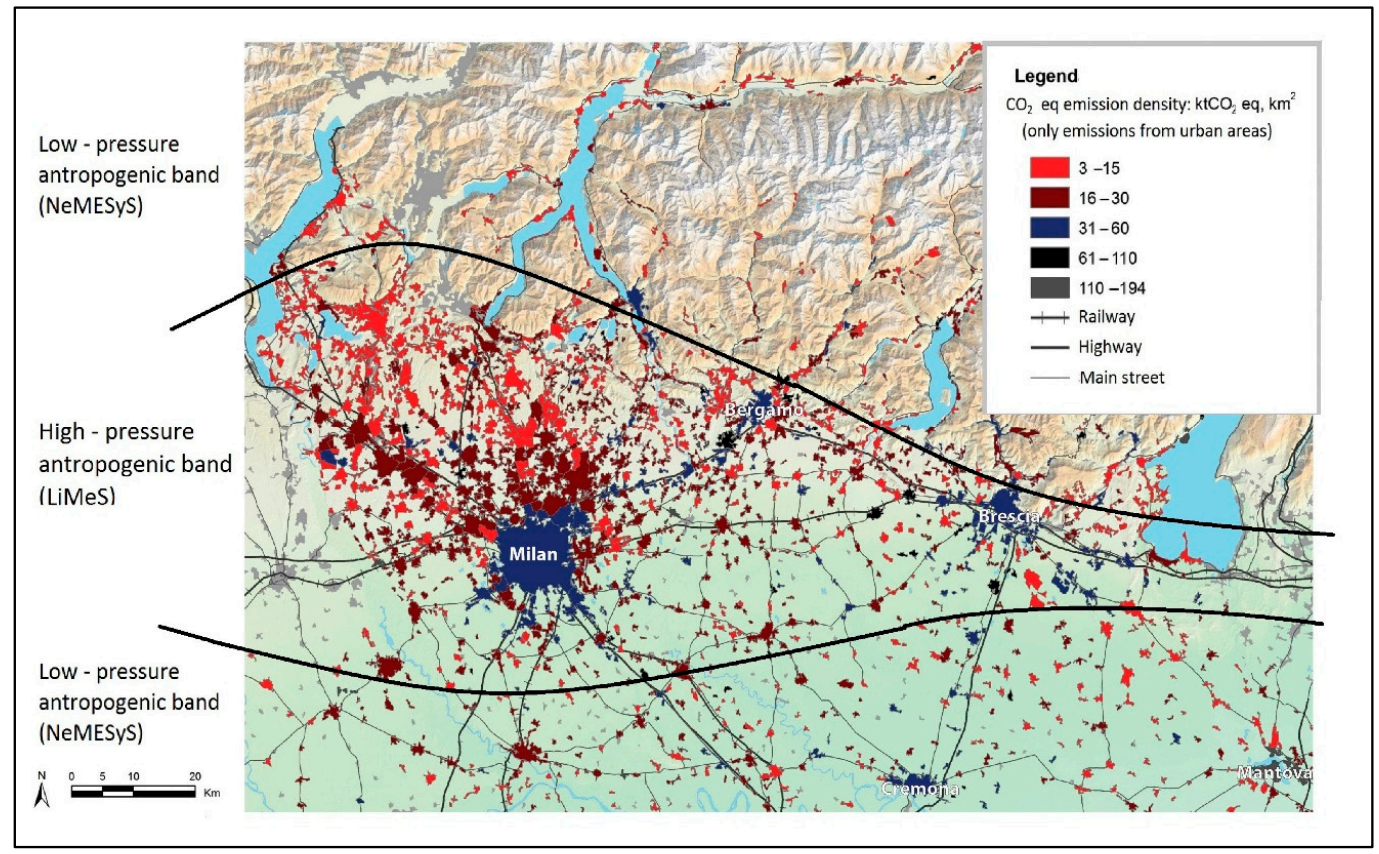

Figure 3. $\mathrm{CO}_{2}$-equivalent emission density for urban areas $\left(\mathrm{ktCO}_{2} \mathrm{eq} / \mathrm{km}^{2}\right)$ in the Lombardy Region [37].

The relationship between the total emission density and the housing density highlights the non-residential contribution to the emission component. Significant are the cities of Mantova and Cremona, which are characterized by the distribution and processing of fuel (petroleum), and steel manufacturing. Analogous with the abnormalities highlighted by the total emissions, along the main rivers there are some municipalities in which there are (hydroelectric) energy production activities. The urban phenomenon that are highlighted in this image is that of the spatial dimension of cities: the dimensions evaluated in the already mentioned PRIN 2007 project are of about $70 \mathrm{~km}$ for the Milan area and about $20 \mathrm{~km}$ for that of Brescia, and correspond to those identified in the relationship to the density of emissions. 
The $\mathrm{PM}_{2.5}$ emission density indicator highlights the strong correlation between the provincial capitals of Bergamo and Brescia (previously less obvious) while reducing that with Milan. The non-continuity of this phenomenon is due to the high artificialization of the Milan area. Conversely, in the case of Mantova and Cremona, the reduced urbanized surfaces and the presence of high emissions make the indicator rise to higher chromatic scale values (Figure 4).

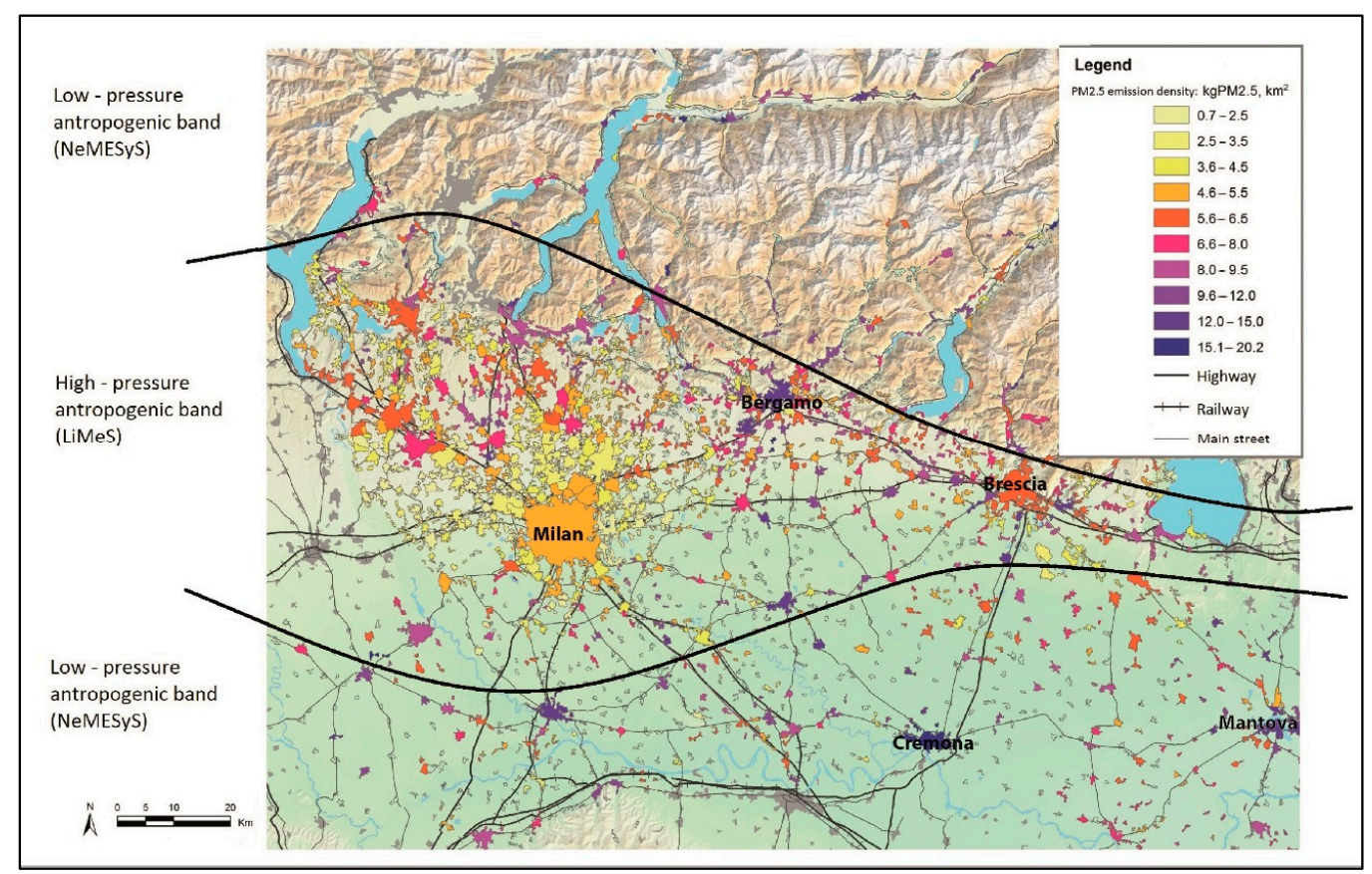

Figure 4. $\mathrm{PM}_{2.5}$ emission density for urban areas $\left(\mathrm{kg} \mathrm{PM}_{2.5} / \mathrm{km}^{2}\right)$ in the Lombardy Region [37].

Looking now at the more detailed case study of the province of Brescia, the overall data on absolute emissions and pro-capita emissions show high values for both indicators, or higher than usual data compared to the average provincial reference value $\left(50,000 \mathrm{t} \mathrm{CO}_{2}\right.$-eq and $10 \mathrm{t} \mathrm{CO}_{2}$-eq per inhabitant). This is due to the presence of industrial activities and related traffic generated in the Brescia Valleys. It should be noted that the predominantly industrial structure of steel manufacturing is historically located in the valleys near streams or raw materials (iron, coal, etc.) required for the production processes. In the 1990s, following a crisis in this sector, there was a progressive reorganization of the iron and steel industry with a partial move to the more accessible plains.

The emissive contribution of intensive agricultural production in the area of the plains, though generally with values only slightly above the provincial average, needs to be further decreased, by subsequent investigations aimed at a better understanding of the impact it generates on the territory and also in relation to food supply needs.

These analyses relate to the $\mathrm{CO}_{2}$-equivalent density of the macro-sector 10: agriculture subdivided subsequently into 'agriculture' and 'livestock' sections, and referring to the utilizable agricultural surface. The decade of 2000-2010 saw a reduction of the UAS both at the national level (-2.5\%) and in Lombardy (-5.1\%) while the province of Brescia saw an increase of UAS of $1.3 \%$.

The main indicator, represented in the thematic map in Figure 5, shows how the emission values that exceed the provincial average refer almost exclusively to the Brescia plain. Some exceptions are found in the valleys, because of very low values of UAS, which determine a slightly higher indicator than the average, which is set at $1000 \mathrm{tCO}_{2}$-eq. The indicators of emission density from agriculture and livestock (Figure 6) show how much the emission incidence is unbalanced towards the latter. 


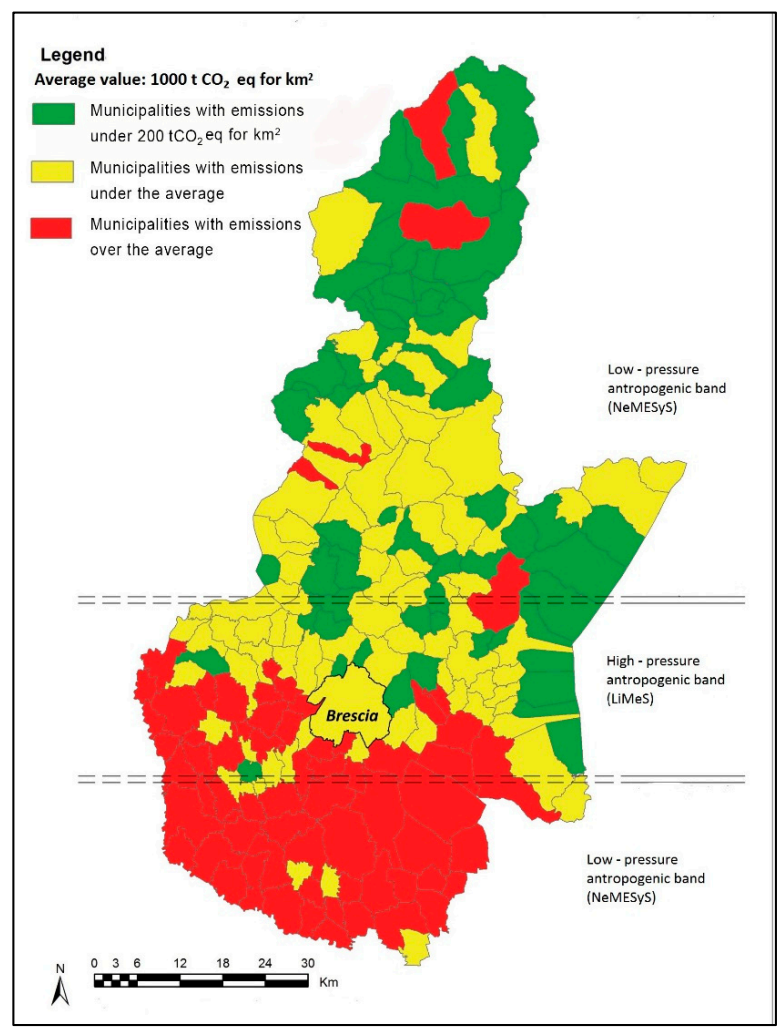

Figure 5. The relation between $\mathrm{CO}_{2}$-equivalent emission density of macro-sector 10-agriculture, and the Utilizable Agricultural Surface (UAS) in the province of Brescia. Chromatic scale legend: values exceeding the provincial average are in red, values close to the provincial average are in yellow and values lower than the provincial average are in green [37].

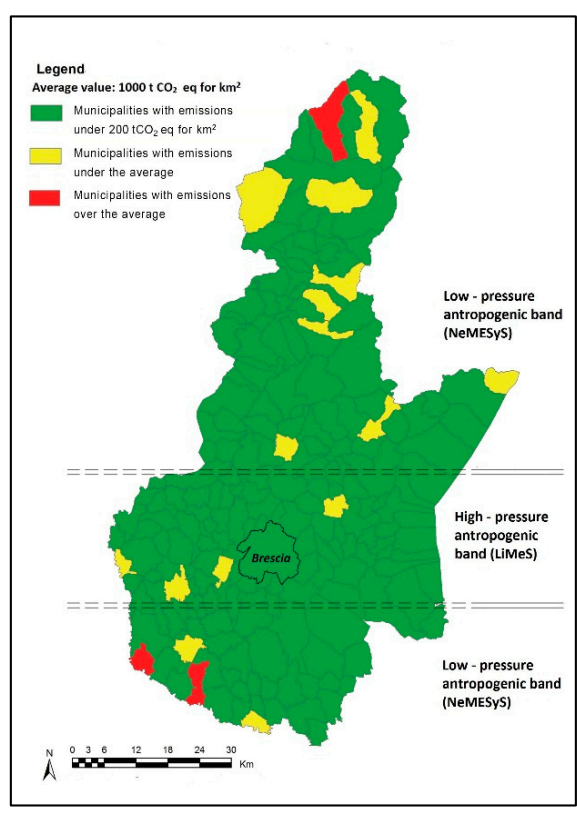

(a)

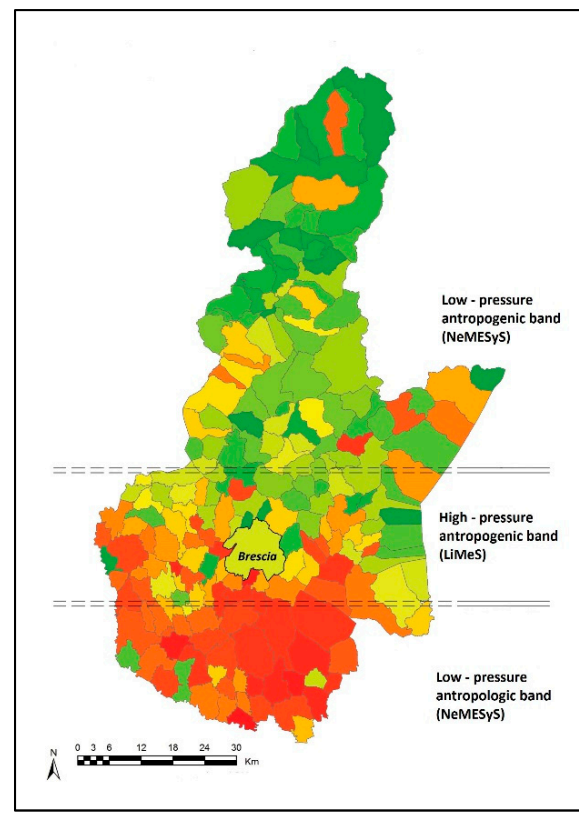

(b)

Figure 6. The relation between (a) $\mathrm{CO}_{2}$-equivalent emission density from agriculture and (b) livestock and Utilizable Agricultural Surface (UAS) in the province of Brescia. Chromatic scale legend: values exceeding the provincial average are in red, values close to the provincial average are in yellow and values lower than the provincial average are in green [37]. 


\section{Discussion}

The case study, as mentioned in the introduction, presents the emissive problem at its highest level. The features of urban density, sprawl and livestock systems fit within the conditions of the surrounding area (Po Valley), and consequently it is extremely representative.

The national drop in emissions (showed in Table 1) is probably attributable to the economic crisis, which has had a significant impact on energy production and manufacturing.

Already in the first phase of the investigation on a regional scale, with reference to Lombardy, or Northern Italy, there have been confirmations of complex phenomena in the area: just the emissions allow us to identify the typical characteristics of the LiMeS theory of cities [23] at the scale given to the Lombardy Region.

While on the scale related to the Province of Brescia, significant emissions were also noted in the plain due to the presence of livestock, and in the mountain ranges to the north due to the presence of specific steel processing, aluminum and paper factories. In reference to $\mathrm{CO}_{2}$-equivalent emission density, it should be noted that in the province of Brescia there is a high presence of pig farms [38]. In the Lombardy region, pig farms account for about $50 \%$ of the national production and are located predominantly in the provinces of Brescia, Mantova and Cremona. In particular, ISTAT (Italian National Institute of Statistics) reports that $16 \%$ of pigs in Italy are bred in the province of Brescia $(1,325,421$ animals) to which must be added $15 \%$ of chickens $(14,969,749$ animals) and $8 \%$ of cattle $(342,654$ animals) [38]. It is evident from these figures (Figures 5 and 6) that livestock farming is strongly present and rooted in this area.

The study of the macro-sectors related to land use, notwithstanding the proxies proposed, allows us to suggest some preliminary reflections regarding possible actions to be taken into account together with the integrated policies on emission reduction already in place at the national level:

- Macro-sector 3. Industrial combustion (22\%): encourage the upgrading of industrial areas, for example by creating green filter areas between these and the residential area, in order to mitigate $\mathrm{CO}_{2}$ emissions if these cannot be reduced at the source. It is to be noted that direct incentives to improve industrial buildings are not foreseen at this time (at the national level only the "Conto Termico" of DM 28/12/2012), while there are some proposed for residential areas.

- Macro-sector 10. Agriculture (17\%): the presence of livestock farms are significant and it is possible to stimulate the recovery of agricultural by-products for internal use.

In 2014, the Italian Ministry of the Environment had signed an agreement to improve the air quality of the Po Valley. Consequently, the Ministry of Agriculture, Food and Forestry had defined a guideline to reduce the emissions coming from agricultural and livestock activities. A recent study that tried to evaluate the technical and economic feasibility of this guideline concluded that the technical solutions regarding livestock management are more feasible than significant and expensive interventions in stalls [39]. The livestock management in the future will be very different [16] and the planners could work in this sector, especially giving suggestions and directions for livestock management under the concept of the best available technology, for example for spillers, biogas plants, etc. In the Po Valley, the spatial planning of agricultural activities will be more important than in other areas due to the high presence of animals and agricultural activities (sometimes exceeding human beings).

In territories with a significant agricultural sector, the Strategic Environmental Assessment of local plans needs to focus more on GHG emission scanning as proposed in Figure 7. The competent body that could set up and monitor this is the region, but the related spatial scale is not suitable. Governance activities (working groups) led by the region could help groups of municipalities to coordinate common actions to reach agricultural sustainability at the local level.

Spatial planning will take advantage of an integrated view and skills to achieve integrated policies: urban policies, agricultural policies, GHG emissions reduction policies and their connections. 


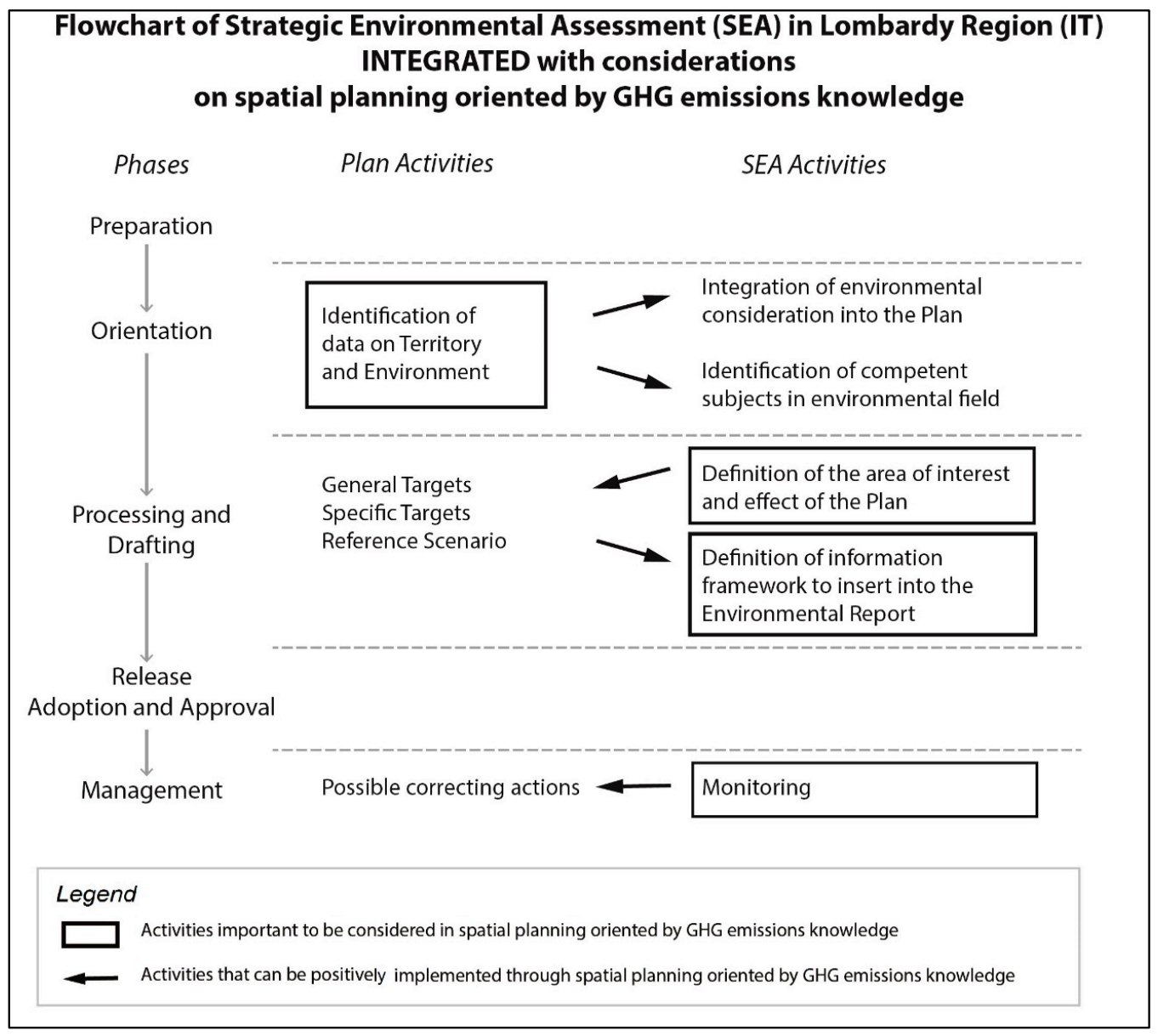

Figure 7. Flowchart of Strategic Environmental Assessment (SEA) integrated with considerations on spatial planning oriented by Anthropogenic Greenhouse Gas (GHG) emissions knowledge.

\section{Conclusion}

The above analysis demonstrated that an integrated reading of urban and rural land uses in relation to GHG emissions is feasible at the regional level. The analysis starts with a synthetic methodology that is based on GHG emissions data and makes it possible, through their territorial mapping, to read their effects and to verify the phenomena apparently linked with the land use. This allows us to monitor the territory by developing a critical reading of a vast area, aimed at improving local policies that have territorial implications. Therefore, this kind of measurement is relevant to land use policies and planning.

The use of open-source data makes this reading replicable in time and easily transferable to other territories [40] with some limitation at the national level, since not all regions collect data with the same methodology and level of municipal segregation. Monitoring action measures the effects of the emission reduction policies in specific sectors and their impact on land use (for example, as it happens for land use and mobility, e.g., [41]). Cities are by nature energy "greedy", so most of the investigations in Italy are focused on the urban environment. "Models, methods, and research in several disciplines have been developed for urban land-use planning. By contrast, rural planning has only been partially considered and is almost always approached from the perspective of increased crop or forest production" [36]. In some cases, such as the Po Valley, it is evident that the emissions in the agricultural area are far from negligible and require specific intervention and land use policies aimed at improving the current conditions.

GHG emissions (mainly resulting from the combustion of fossil fuels for energy production) are the common element of almost all human activities in the territory. The use of an expeditious 
method that is based on sufficiently segregated existing databases (such as the macro-sectors of the INMAR database) allows for a more expanded understanding and offer a better territorial management perspective. More research effort is needed in order to better understand the highly variable nature of GHG emission in relation to the complexity of social, economic and spatial phenomena of a region. The spatial analysis through precise emission classes associated with land use will also enable to avoid the generalization of territorial characteristics, helping to identify specific actions to be taken on a local scale and based on energy-conscious urban planning. Helping to develop the framework already advocated by Tzilivakis [10] that is working on a broader and more strategic perspective in order to "determine the overall benefit of operations for emission reductions" [42].

Livestock management and energy planning are not the only ambits in which spatial planning could help to lead decisions: the knowledge achieved through the analysis connecting land use and GHG emission in rural areas (and also urban ones) could integrate the Strategic Environmental Assessment (SEA) of local plans and could present a clear and broad framework for municipalities (for small municipalities, this framework is not easy to implement even in general terms [43]).

It is important to note some limitations of this study: as already mentioned, the most relevant aspect is related to the use of open-source data especially regarding data quality and disposal, spatial updates and, above all, the methodology used to collect them. The other aspect is related to CLC spatial information used as a proxy to select artificial surfaces. This must be carefully verified by research deepening the national protocols for collecting the data.

In synthesis, the Italian case study and the relative reflections are emblematic and useful for researchers and spatial planners, especially for those who work in growing countries (i.e., China and India) and also former communist EU countries $[5,29]$ with similar urban or rural features and in which the phenomena are not yet so advanced. This approach can be particularly useful for leading the territorial systems within which the city fits, and is a fundamental element of moving toward higher levels of sustainability. The spatial planning targets oriented by GHG emissions knowledge could try to achieve:

- A higher quality of agricultural and livestock products (instead of high quantities);

- Better touristic activities in rural areas without pollution or with reduced interference; and

- A better quality of life and health for citizens.

Author Contributions: Data curation, A.R.; Investigation, A.R. and M.P.; Methodology, M.P. and M.T.; Supervision, M.T.; Writing—original draft, A.R.; Writing—review and editing, A.R. and M.P. All authors have read and agreed to the published version of the manuscript.

Funding: This research received no external funding.

Acknowledgments: We thank Marco Rosini for his technical support. We thank Alessandro Berni: some elaborations starting from his master's thesis [37].

Conflicts of Interest: The authors declare no conflict of interest.

\section{References}

1. IPCC. Climate Change 2014. Synthesis Report; IPCC: Geneva, Switzerland, 2014; p. 151.

2. UN-HABITAT. Cities and Climate Change: Global Report on Human Settlements 2011; UN-HABITAT: London, UK; Washington, DC, USA, 2011.

3. EEA. Annual European Union Greenhouse Gas Inventory 1990-2016 and Inventory Report 2018; EEA: Brussels, Belgium, 2018.

4. IPCC. 2014: Annex II: Glossary. In Climate Change 2014: Synthesis Report. Contribution of Working Groups I, II and III to the Fifth Assessment Report of the Intergovernmental Panel on Climate Change; Mach, K.J., Planton, S., von Stechow, C., Eds.; IPCC: Geneva, Switzerland, 2014; pp. 117-130.

5. Hernik, J.; Noszczyk, T.; Rutkowska, A. Towards a better understanding of the variables that influence renewable energy sources in eastern Poland. J. Clean. Prod. 2019, 241, 118075. [CrossRef] 
6. Kazak, J.; Dziezyc, H.; Forys, I.; Szewranski, S. Indicator-based analysis of socially sensitive and territorially sustainable development in relation to household energy consumption. Eng. Rural Dev. 2018. [CrossRef]

7. Lin, T.; Yu, Y.; Bai, X.; Feng, L.; Wang, J. Greenhouse Gas Emissions Accounting of Urban Residential Consumption: A Household Survey Based Approach. PLoS ONE 2013, 8, e55642. [CrossRef] [PubMed]

8. Mi, Z.; Guan, D.; Liu, Z.; Liu, J.; Viguié, V.; Fromer, N.; Wang, Y. Cities: The core of climate change mitigation. J. Clean. Prod. 2019, 207, 582-589. [CrossRef]

9. Kennedy, C.; Demoullin, S.; Mohareb, E. Cities reducing their greenhouse gas emissions. Energy Policy 2012, 49, 774-777. [CrossRef]

10. Tzilivakis, J.; Warner, D.J.; Green, A.; Lewis, K.A. Spatial and temporal variability of greenhouse gas emissions from rural development land use operations. Mitig. Adapt. Strateg. Glob. Change 2017, 22, 447-467. [CrossRef]

11. Westhoek, H.J.; van den Berg, M.; Bakkes, J.A. Scenario development to explore the future of Europe's rural areas. Agric. Ecosyst. Environ. 2006, 114, 7-20. [CrossRef]

12. Henderson, B.; Falcucci, A.; Mottet, A.; Early, L.; Werner, B.; Steinfeld, H.; Gerber, P. Marginal costs of abating greenhouse gases in the global ruminant livestock sector. Mitig. Adapt. Strateg. Glob. Change 2017, 22, 199-224. [CrossRef]

13. Feliciano, D.; Slee, B.; Hunter, C.; Smith, P. Estimating the contribution of rural land uses to greenhouse gas emissions: A case study of North East Scotland. Environ. Sci. Policy 2013, 25, 36-49. [CrossRef]

14. Knapczyk, A.; Francik, S.; Pedryc, N.; Hebda, T. Bibliometric analysis of research trends in engineering for rural development. In Proceedings of the 17th International Scientific Conference Engineering for Rural Development, Jelgava, Latvia, 23-25 May 2018; pp. 700-707.

15. Seravalli, G. Dimensioni e crescita delle città in Europa: l'incertezza danneggia soprattutto le città medie. Sci. Reg. Ital. J. Reg. Sci. 2016, 16, 91-108. [CrossRef]

16. Lesschen, J.; van den Berg, M.; Westhoek, H.; Witzke, H.; Oenema, O. Greenhouse gas emission profiles of European livestock sectors. Anim. Feed Sci. Technol. 2011, 166-167, 16-28. [CrossRef]

17. AA.VV. Agri-Environmental Schemes: How to Enhance the Agriculture-Environment Relationship; Science Communication Unit, UWE Bristol, Ed.; European Commission DG Environment: Bristol, UK, 2017; Volume 57.

18. ISTAT. $15^{\circ}$ Censimento Generale Della Popolazione e Delle Abitazioni. Sintesi dei Primi Risultati; ISTAT: Roma, Italy, 2012.

19. ISTAT. Annuario Statistico Italiano 2015; ISTAT: Roma, Italy, 2015.

20. EEA-FOEN. Urban sprawl in Europe; EEA-FOEN: Luxembourg, 2016; p. 140.

21. Marcotullio, P.; Sarzynski, A.; Albrecht, J.; Schulz, N. A Top-Down Regional Assessment of Urban Greenhouse Gas Emissions in Europe. Ambio 2014, 43, 957-968. [CrossRef] [PubMed]

22. ISTAT. Totale Della Popolazione Residente al $1^{\circ}$ Gennaio 2017; ISTAT: Roma, Italy, 2017.

23. Busi, R.; Pezzagno, M. Una Città di 500 km: Letture del Territorio Padano; Gangemi: Roma, Italy, 2011.

24. Pezzagno, M.; Docchio, S. Virtual or real Megaregions? The case of Linear metropolitan System in Northern Italy. In Virtual Cities and Territories; Nuno Norte Pinto, J.A.T., Santos, M., de Deus, R., Eds.; Nova University of Lisbon: Lisbon, Portugal, 2011.

25. Docchio, S. Problematiche Gestionali e Caratterizzazione dei Sistemi Metropolitani Lineari: Elementi di Metodo; University of Brescia: Brescia, Italy, 2012.

26. Briganti, G. Un'introduzione Allo Studio Della Dispersione di Inquinanti in Atmosfera in Condizioni di Calma di Vento; ENEA: Pisa, Italy, 2007; Volume 62.

27. EUROSTAT. Eurostat Regional Yearbook; EUROSTAT: Brussels, Belgium, 2016.

28. EUROSTAT. Agriculture, Forestry and Fishery Statistics; Publications Office of the European Union: Luxembourg, 2017; p. 170. 
29. Grešlová, P.; Štych, P.; Salata, T.; Hernik, J.; Knížková, I.; Bičík, I.; Jeleček, L.; Prus, B.; Noszczyk, T. Agroecosystem energy metabolism in Czechia and Poland in the two decades after the fall of communism: From a centrally planned system to market oriented mode of production. Land Use Policy 2019, 82, 807-820. [CrossRef]

30. Gingrich, S.; Krausmann, F. At the core of the socio-ecological transition: Agroecosystem energy fluxes in Austria 1830-2010. Sci. Total Environ. 2018, 645, 119-129. [CrossRef] [PubMed]

31. EEA. Agriculture; EEA: København, Denmark, 2011; p. 8.

32. EU. Regulation (EU) 2018/842 of the European Parliament and of the Council of 30 May 2018 on binding annual greenhouse gas emission reductions by Member States from 2021 to 2030 contributing to climate action to meet commitments under the Paris Agreement and amending Regulation (EU) No 525/2013. In EUR-Lex-32018R0842; Relevance, E., Ed.; Official Journal of the European Union, 2018; Volume 2018/842, Available online: https:/eur-lex.europa.eu/legal-content/EN/TXT/PDF/?uri=CELEX:32018R0842\&from=EN (accessed on 19 December 2019).

33. Richardson, S. Joint EMEP/CORINAIR. In Atmospheric Emission Inventory Guidebook, 2nd ed.; EEA: Copenhagen, Denmark, 1999.

34. IPCC. Task Force on National Greenhouse Gas Inventoris; Eggleston, H.S.B.L., Miwa, K., Ngara, T., Tanabe, K., Eds.; IPCC (IGES): Hayama, Kanagawa, Japan, 2006.

35. EEA. CLC 2006 Technical Guidelines; Publications Office of the European Union: Luxembourg, 2009.

36. Santé-Riveira, I.; Crecente-Maseda, R.; Miranda-Barrós, D. GIS-based planning support system for rural land-use allocation. Comput. Electron. Agric. 2008, 63, 257-273. [CrossRef]

37. Berni, A. Primi Approcci All'analisi Delle Emissioni di Gas Serra. Il caso di studio di Brescia. Master Thesis, University of Brescia, Brescia, Italy, 2016.

38. ISTAT. $6^{\circ}$ Censimento Generale dell'Agricoltura. Atlante dell'agricoltura italiana; Lipizzi, G.B.F., Giordano, F.C.P., Eds.; ISTAT: Roma, Italy, 2013.

39. De Roest, K.; Rossi, P.; Valli, L.; Pacchioli, M.T. Prime Valutazioni dei Costi delle Misure per la Riduzione delle Emissioni in Atmosfera di Ammoniaca delle Attività Zootecniche; Centro Ricerche Produzioni Animali-CRPA Spa: Reggio Emilia, Italy, 2016; p. 29.

40. Alhamwi, A.; Medjroubi, W.; Vogt, T.; Agert, C. GIS-based urban energy systems models and tools: Introducing a model for the optimisation of flexibilisation technologies in urban areas. Appl. Energy 2017, 191, 1-9. [CrossRef]

41. Tira, M. L'interazione tra uso del suolo e mobilità. In Pianificare per la Sostenibilità Energetica della Città; La Greca, P., Tira, M., Eds.; Maggioli Editore: Sant'Arcangelo di Romagna, Italy, 2017; pp. 203-212.

42. AA.VV. Greenhouse gas emissions and rural development in the EU. In Science for Enviromental Policy; Science Communication Unit-University of the West of England (UWE) Bristol, Ed.; European Commission DG Environment: Brussels, Belgium, 2016; p. 2.

43. Richiedei, A.; Mazzetti, F. Pianura Sostenibile: Un monitoraggio socio-ambientale decennale. In Pianura Sostenibile. Dieci Anni di Proposte e Riflessioni; Edizioni Studiorum: Brescia, Italy, 2019; pp. 86-91.

(C) 2020 by the authors. Licensee MDPI, Basel, Switzerland. This article is an open access article distributed under the terms and conditions of the Creative Commons Attribution (CC BY) license (http://creativecommons.org/licenses/by/4.0/). 